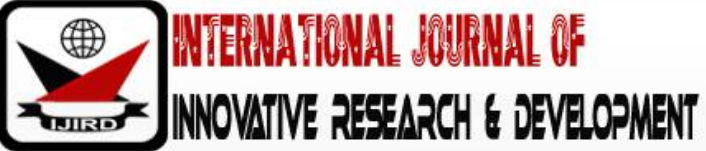

ISSN 2278 - 0211 (Online)

\section{An Appraisal of NBS Coverage of Communal Conflict in Nasarawa State, Nigeria: Focus On the 2013-2015 Herdsmen/ Farmers Conflict}

\author{
William Musa Madaki \\ Principal Lecturer, Department of Mass Communication \\ Nasarawa State Polytechnic, Lafia, Nigeria \\ Dr. Gbaden Jacob Chiakaan \\ Senior Lecturer, Department Of Mass Communication \\ Taraba State University, Jalingo, Nigeria \\ Anthony Orjiako \\ Assistant Lecturer, Department Of Mass Communication \\ Nasarawa State Polytechnic, Lafia, Nigeria
}

\begin{abstract}
:
This study is titled: "An Appraisal of Nasarawa Broadcasting Service (NBS) Coverage of Communal Conflicts in Nasarawa State, Nigeria: Focus on Herdsmen and Farmers Conflicts." Specifically, the study examines the way and manner NBS covered the 2013-2015 crisis between Fulani herdsmen and farmers in Nasarawa State, Nigeria. Data were collected and analysed both quantitatively and qualitatively. Adopting the social responsibility theory of the press, the study discovers that NBS was found lacking in its role as promoter of unity and peace among the various ethnic/religious groups in the State as demonstrated in its partial, biased and unprofessional coverage of the crisis. Findings have further revealed that rather than helping in managing the crisis, the station worsened it as it was found of accusing the various farming groups of being guilty party in the crisis. The study discovers, again, that the station was not even conscious of the Nigeria Broadcasting Code provided by NBC to be guiding all broadcast stations in reporting crisis or emergencies. Among other things, the study, therefore, recommends strict supervision and penalty against stations who violate the NBC code, training and recruitment of professional broadcasters.
\end{abstract}

Keywords: Conflict, coverage, herdsmen, farmers and social responsibility

\section{Introduction}

Conflict, it is argued, is a part and parcel of nature. Human beings, on individual or group basis often experience conflict. Conflict exists within individuals, between one person and another person, between one group and another group. In Nigeria, we often read about the political conflicts that occurred in the 60s leading to the collapse of the first republic, the census crisis of still of the 60s, the Nigerian civil war of 1967, the Ife-Modekeke conflict, Tiv/ Jukun crisis of the 1990s and 2001, the Jukun/ Kuteb conflict of 1990s, the Plateau crisis between Hausa settlers and indigenes in 2010, and many others. These conflicts, are inclined to ethnicity, religion, militancy, terrorism, youth restiveness, electoral violence (www.ajol.info). The implication is that as human beings and more especially, as Nigerians, we have no choice than to live with conflict.

Conflict exists in all societies. The most disturbing conflict however, is the one that is violent. This kind of conflict does not only result in destruction of lives and property, but it also impedes societal peace, unity and development (Ajala, 2001). A society that is bedeviled by violent conflicts, Chiakaan and Tsegyu (2008) have observed, can never grow and develop. Chiakaan and Tsegyu have noted further that in a rancorous atmosphere, no business, can be effectively carried out as schools will be closed down, market and business environments will be unsafe, lives and property will be lost, psychologically, people will not be secured. It is because of its negative consequences that conflict management is what no reasonable society plays with.

While conflict has many drawbacks associated with it, it is argued by some scholars that conflict brings about positive changes that can attract societal development. (Tella, Apara, Aliyu and Dawood, 2010). This good side of conflict can only be possible, however, in a situation where there is an effective machinery of managing the conflict when it occurs.

Since its creation on 1 st October, 1996, Nasarawa State has witnessed many violent conflicts. Among such violent crisis was the one of 2001 between the Tiv and Alago ethnic groups in the Southern-Zone. The 2001 crisis occurred during the governorship period of Senator Abdullahi Adamu. Between 2013-2015, during the leadership of Governor Aliyu Akwe 
Doma, the State still witnessed another violent conflict that appeared to be more serious and dangerous than the previous ones. This crisis involved the Fulani pastoralists and farmers.

Even though the crisis appeared to be more concentrated and devastating in the Southern-Senatorial Zone of the State, it actually covered the entire state, extending its tentacles to neighboring States like Benue, Plateau, Taraba and Abuja, the Federal Capital Territory (FCT). The crisis was more dangerous because it threatened the very foundation on which Nasarawa State was built in the following ways:

- The peace and unity among the various groups in the State was destroyed;

- Many lives and property were lost;

- Many people were displaced from their homes; they were forced to become refugees in their land;

- Everybody in the state was affected psychologically or otherwise;

- It fueled and promoted tribal hatred and insecurity generally;

- The State was further underdeveloped;

- Government had to spend money in order to manage the crisis; money that was supposed to have been used in developing the State.

The grievous nature of the crisis attracted serious efforts from the federal and state governments, corporate organizations to bring it to an end. The mass media both in the State and outside the State, as socially demanded on them, were also actively involved in quelling the crisis. While their efforts, in this regard, were highly appreciated by some people, some people appeared to be discontent with the way and manner they covered the crisis. The latter group criticized the media of being biased in their reportage of the crisis thereby worsening it.

More accused in its coverage and reportage of the crisis was the Nasarawa Broadcasting Corporation, the only public broadcasting station owned by the Nasarawa State Government. The crux of this study, therefore, is to appraise the way and manner NBS covered the pastoralist/ farmers crisis that occurred in Nasarawa State between 2013-2015.

\subsection{Statement of the Problem}

The conflict involving farmers and pastoralists in Nasarawa State between 2013-2015 had very dangerous consequences on the survival and development of the State and Nigeria as a whole. As usual with all violent crises, lives were lost, property worth billions of naira were destroyed, business activities were disrupted, the fundamental human rights of people in the State especially those in the affected areas were tempered with; anarchy was released upon the State particularly in the rural areas. Roads in the State and those linking the State with other States became homes of looters and robbers; they were not safe to guarantee free movement. The destructive nature of the crisis compelled various stakeholders to swung into action in order to put an end toit.

The mass media, being a part and parcel of the society, and demonstrating their corporate responsibility as socially demanded on them, also rose up to contribute their quota towards managing the crisis. Incidentally, many people expressed concern about the way and manner the mass media, especially Nasarawa Broadcasting Service used to cover and present news on the crisis. People in this category have perceived this State-owned broadcast organization to have sacrificed ethical standard required by the National Broadcasting Commission (NBC) in its code since 1993, in covering and reporting crisis; they accused it of being biased.

This is a very unfortunate situation because if this accusation is true, it implies that the future of Nigeria as a country of multiple elements, is in a very serious doubt and as such calls for urgent and proactive approaches towards correcting the abnormally. This study, therefore, investigates the Nasarawa Broadcasting Service coverage of the 20132015 crisis between the Fulani herdsmen and farmers in Nasarawa State.

\subsection{Objectives of the Study}

The broad objective of this study is to appraise the coverage of crises in Nasarawa State by the mass media. Specifically, however, the study is carried out to:

- Determine the accessibility of people of Nasarawa State to NBS programmes.

- Find out whether people were satisfied by the way and manner NBS covered and reported the 2013-2015 conflicts between herdsmen and farmers in Nasarawa State.

- Ascertain the level of ethical professionalism exhibited by NBS in the coverage of the 2013-2015 conflict between herdsmen and farmers.

- Determine whether the coverage by NBS on the 2013-2015 herdsmen/ farmers crisis deescalated the conflict.

\section{Literature Review}

Nasarawa Broadcasting Service, established in 1996, as NBS is a broadcasting organization that is owned by the government of Nasarawa State, Nigeria. As a public broadcasting station, the station is managed by public funds usually derived from the people of the State through taxation (Sambe, 2005, and Ciboh, 2007). Specially, the radio station was established to perform the functions which are usually identified with other public mass media especially broadcast media. Since the birth of mass media in Nigeria and societies, scholars have always associated them with certain fundamental and conventional functions. These functions, Okunna (1999), Wright (1975), Dominick (1999), Ajala (2001) and many other scholars, have unraveled them as surveillance, educational, correlation, socialization, entertainment, cultural preservation and promotion.

These functions of the news media have made them, in whatever society they exist, to be very important; they have made them to be considered indispensible tools for achieving peace, harmony and development more especially for 
developing societies (Madaki, 2019). Due to the importance of the media of mass communication in the Nigerian set up, the mass media are considered as the "forth arm of the government" (Ciboh and Iyorkyaa, 2004).

The indispensability of the media of communication in any given society, Thomas Jefferson,a former American President once declare that if faced with a situation of making a choice between information and government, he would not delay in choosing information, for any society that lacks information or means of acquiring the information is bound to fall (Madaki and Kudu (2014); Chiakaan and Ahmad (2016).

The perceived exigency of the mass media specially, the broadcast media was what even necessitated the introduction of broadcasting in Nigeria by the colonialists. Perceived inability of the Nigeria Broadcasting Service to be non-partisan, impartial in its operations, however, Ciboh (2007) observes, made Nigerians, especially nationalists agitating for independence to clamor for regional stations. The belief of people at the regions was that regional stations would be more effective in covering and projecting their interests.

As a country of multiplicity of cultures due to tribal, religious and political differences, the broadcast stations are expected to ensure that they are fair to all in their operations. They are, regardless of who owns them, whatever interest is involved, expected to be impartial in their operations. Reinforcing the ongoing debate, the 2000 report of the World Radio and Television Council on Public Broadcasting describes the principles of independent public service broadcasting as being universality, diversity, independence and distinctiveness. The report, as quoted by Buckley, Duer Mendel, Osiochru, Price and Raboh (2008) in Chiakaan (2013, p.43) among other things, preaches the independence of broadcast stations from commercial pressures and political influences; a concern for national identity and culture, the impartiality as well as the independence of programmes.

Broadcast stations are expected to be guarded by these principles of independence and impartiality in order to enable them carry out their social responsibility role and development. In Nigeria, this demand appears to be more on the broadcast media due to the diverse nature of the elements that have formed it. The situation appears to be more so due to the volatile and hostile nature of the Nigerian milieu as products of tribal, cultural, religious, political and sectional differences.

Of all the broadcast media, radio seems to be the most powerful in Nigeria and other developing societies. Sharing a position similar to this, Ojebode (2003, p.87) posits that "radio is now everywhere; the taxi driver in Lagos, the itinerant fisherman in Kolo creeks, the farmer in Tiv land and the roving nomad behind his cattle join others across the planet to pursue their daily endeavors with one faithful comrade-radio."

Radio is accessible to every class of people; both literates and illiterates, distance does not mean anything to it, electricity is not much required for its consumption like television and others, these attributes have far made radio the most potent tool of managing conflicts in Nigeria by ensuring unity and peace among the divergent elements for development purposes.

Aware of the penetrating ability of the broadcast media with radio inclusive, and in order to ensure that broadcast stations are not used by unscrupulous elements to cause or aggravate warring situations, the Nigerian government has set up a body to be regulating activities of broadcast stations; the body is known as National Broadcasting Commission (NBC). Established in 1992, the commission has what is called, Nigeria Broadcasting Code. The code (2005, p.20) contains:

The universal aims and objectives of broadcasting with specific application to Nigeria. The purpose is to guide broadcasting to apply the provisions of the code and to assist the public to uphold them as the benchmark for their "...right to quality broadcasting.

Section 5, subsection 5.0 (5.5.0) of the 2005 code provides clear guidelines on how broadcast stations can cover crises and emergencies in Nigeria thus:

- At all times, the coverage of a disaster or crisis shall include where available information on evacuation, public safety, relief sites and shelters.

- News and commentary on a crisis or emergency shall be presented in a professional manner by relying on information from the accredited disaster management organizations.

- Except where it is useful in the resolution of attendant issues, morbid or graphic details of death, injury, pain and agony or evidence of such shall not be broadcast.

- A broadcaster shall not temper with materials or facts that could usefully ameliorate the pains of the crisis.

- A broadcaster shall not broadcast divisive rhetoric that threatens and compromises the indivisibility and indissolubility of Nigeria as a sovereign State.

Of course, conflicts and disasters must occur in the society. Conflicts, also referred to as crises, Ajala, (2001, p.175) states, "are either violent or non-violent, a crisis can be an act of nature, an intentional event or an unintentional accident." Ajala further notes that "a crisis creates the threat to death and loss of property." This was the kind of situation that Nasarawa State found itself in from 2013-2015 involving Fulani pastoralists and farmers. Specifically, grazing on farm lands, and efforts to prevent the pastoralists from intruding on their farms by farmers was the primary cause of the crisis, the crisis later took tribal and religious dimensions as usual with crises of this nature in Nigeria.

Being a part and parcel of the State, and in order to carry out its constitutionally recognized responsibility, NBS was actively involved in the coverage of the crisis. Whether the station was able to cover the crisis as demanded by the NBC code is what remains unknown which is what this study is out to investigate.

\section{Methodology}

The study employed survey as its design. Survey was deemed more appropriate because it is more natural in studying an issue that is topical and current. Also, it is less expensive, according to Osuala, (2005, p.5) compared to the amount of data obtained from it. 
Even though data was collected from secondary sources, the main source of data was primary through questionnaire. In this regard, structured questionnaire was administered on 394 respondents, out of the sampled 400 using Taro Yamane'sstatistical formula (1964) in Chiakaan (2016, p.92). The respondents were randomly sampled from the three senatorial zones in the State. In this regard, purposive sampling method was adopted in selecting Keana and Doma (Southern Zone), Nasarawa Eggon/Wamba (Northern Zone) and Nasarawa and Toto (Western Zone). The population of all these, according to the 2006 census, as contained in the Federal Republic of Nigeria Official Gazette of 2009 was 749795. Only literate respondents were selected for data collection. Respondents from each selected zone were proportionally determined. To complement data collected from questionnaire, oral interview was also conducted on selected key respondents, one from each sampled local government, totaling six. Three research assistants, properly given orientation, were employed to assist in the data collection exercise. Out of the 394 administered questionnaire, only 388 representing $98 \%$ were collected, the remaining $06(2 \%)$ were lost.

\section{Data Presentation and Analysis}

Data presentation and analysis as based on the retrieved 388 questionnaire only.

\begin{tabular}{|c|c|c|}
\hline Respondents & Frequency & Percentage (\%) \\
\hline Yes & 388 & $100 \%$ \\
\hline No & 00 & 00 \\
\hline Total & 388 & $100 \%$ \\
\hline
\end{tabular}

Table 1: Accessibility of Respondent to NBS

Programmes in Their Areas

Source: Field Survey, 2019

Table 1 indicates that all the respondents said NBS reaches their areas with its programmes. This implies that respondents are exposed to NBS activities and as such could give information that can be authentic, reliable and valid.

\begin{tabular}{|c|c|c|}
\hline Respondents & Frequency & Percentage (\%) \\
\hline I was very satisfied & 62 & $16 \%$ \\
\hline I was satisfied & 24 & $6 \%$ \\
\hline I was not completely satisfied & 110 & $28 \%$ \\
\hline I was not much satisfied & 192 & $50 \%$ \\
\hline No comment & 0 & $0 \%$ \\
\hline Total & 388 & $100 \%$ \\
\hline
\end{tabular}

Table 2: Satisfaction of Respondents with NBS Coverage of the 2013-2015 Fulani Herdsmen and Farmers Crisis in Nasarawa State Source: Field Survey, 2019

Data in Table 2 showed that $62(16 \%)$ of the sampled respondents agreed that they were very satisfied with the way and manner NBS covered the 2013-2015 crisis between the Fulani herdsmen and farmers in Nasarawa State, $24(06 \%)$ said they were satisfied, 110(28\%) expressed total dissatisfaction while 192(50\%) revealed that they were not much satisfied with the way and manner the state-owned broadcast medium covered the crisis between herdsmen and farmers in Nasarawa State. The implication of data collected is that people were disappointed by the coverage and reportage of the 2013-2015 herdsmen/ farmers crisis in Nasarawa State.

\begin{tabular}{|c|c|c|}
\hline Respondents & Frequency & Percentage (\%) \\
\hline The station was fair and objective to the parties in the crisis & 42 & $11 \%$ \\
\hline The station was biased in the coverage & 165 & $43 \%$ \\
\hline $\begin{array}{l}\text { The station was unethical and unprofessional in the coverage of the } \\
\text { crisis }\end{array}$ & 124 & $32 \%$ \\
\hline $\begin{array}{c}\text { The language employed in the coverage of the crisis was offensive } \\
\text { to one party }\end{array}$ & 32 & $8 \%$ \\
\hline The station was not informing people accurately. & 25 & $6 \%$ \\
\hline Total & 388 & $100 \%$ \\
\hline
\end{tabular}

Table 3: Respondents Views on the Way and Manner NBS Covered the 2013-2015

Herdsmen/ Farmers Crisis in Nasarawa State

Source: Field Survey, 2019

Whether respondents were satisfied or not with the way and manner NBS covered the crisis under consideration, it was necessary to find out the reason behind their position. Table 3, therefore, seeks to determine the views of respondents on the way and manner NBS covered the crisis. Out of the sampled 388 respondents, $42(11 \%)$ agreed that the station was not fair and objective, 165(43\%) accused the station of being biased, 124(32\%) indicated the station of being unethical and unprofessional, while $32(08 \%)$ and $25(06 \%)$ respectively said the language employed by the station 
in the coverage of the crisis was offensive to one side and that the station was guilty of inaccurate information to people. Analytically, it can be deduced that NBS was not ethical and professional in the coverage of the 2013-2015 herdsmen/ farmers crisis in Nasarawa State; it was biased.

\begin{tabular}{|c|c|c|}
\hline Respondents & Frequency & Percentage (\%) \\
\hline It helped in managing the crisis to some extent & 62 & $16 \%$ \\
\hline It contributed to the management of the crisis to a large extent & 56 & $14 \%$ \\
\hline It only succeeded in worsening the crisis situation & 152 & $39 \%$ \\
\hline $\begin{array}{c}\text { It succeeded in promoting more hatred and division among the } \\
\text { elements in the State. }\end{array}$ & 96 & $25 \%$ \\
\hline Many people did not have confidence in the station again. & 22 & $6 \%$ \\
\hline Total & 388 & $100 \%$ \\
\hline
\end{tabular}

Table 4: Perceived Outcome of the Way and Manner the 2013-2015

Crisis between Herdsmen and Farmers in Nasarawa State Was Covered by NBS

Source: Field Survey, 2019

Data collected in Table 4 have shown that 62(16\%) were of the belief that the way and manner NBS covered the 2013-2015 herdsmen/ farmers crisis in Nasarawa State helped in managing the crisis to some extent, 56(14\%) sampled respondents believed the coverage contributed in managing the crisis to a large extent, 152(39\%) said it only succeeded in promoting more hatred and division among the people in the State while 20(05\%) believed the coverage made many people not to have confidence in NBS programmes. This implies that rather than help in managing the crisis and installing peace, NBS was worsening the crisis situation, promoting more hatred between the warring parties.

\section{Discussion of Findings}

This study was carried out to appraise the way and manner the 2013-2015 conflict otherwise referred to as crisis between Fulani herdsmen and farmers in Nasarawa State was covered by Nasarawa Broadcasting Service (NBS). Data was collected from respondents with access to NBS programmes in their various areas as can be noticed in Table 1. Incidentally, people seemed not to be satisfied with the way and manner NBS covered the herdsmen/ farmers crisis of 2013-2015. This can be seen in Table 2 where 192(50\%) said they were totally dissatisfied with the way the station covered the crisis. This view was further collaborated by data collected from oral interview. ( 2 opinion leaders from each of the two selected local government areas covered per zone).

Nasarawa State has over twenty different ethnic groups among which are Alago, Tiv, Eggon, Koro, Mada, Gbaggi, Hausa, Beri-Beri-, Gwandara and others. These groups are divided among religious and political lines which make them to be always antagonistic to themselves. As a result of power which radio possesses, a station like NBS, operating in this kind of environment is expected to play a peaceful and unifying role both in a crisis and non-crisis situation. This is what the social responsibility theory of the press cherishes as preaches by McQuail (2005) and also supported by the NBC code.

NBS has been accused of being unethical and unprofessional in the coverage of the crisis as can be seen in Table 3. Oral sources supported this view pointing accusing fingers against NBS clearly favouring the Fulani herdsmen in their stories about the crisis. The station was found of associating groupswho were farmers in the crisis with names like Tiv Militia, Koro Youth, Armed Gbagyi Youth, Obatse Militia Group, and such other derogatory names; always blaming them each time there was a clash with the herdsmen. Of course, oral sources have also revealed that the herdsmen were being presented as innocents who were always seen carrying sticks with armless weapons being attacked, killed and their cows rustled away.

It is glaring that NBS negated the principles of fairness and objectivity. This further implies that the station violated the NBC code (5.5.2) which forbids broadcast stations from presenting "news or commentary on a crisis or emergency" in an unprofessional manner. The station, by that act, did not live up to the ethical demands of the social responsibility theory. The stations' coverage of the crisis only succeeded more in worsening the crisis situation and already polarized Nasarawa State and Nigeria as a whole as attested by 153(39\%) in Table 4.

\section{Conclusion}

Broadcast stations operating in any society, developed or developing are regulated by government. This is to ensure that they do not embark on any activity that can put that society in jeopardy given the penetrating, intruding power of broadcasting. Particularly, in a developing society like Nigeria, broadcasting is expected to play a unifying role, always promoting peace, it is expected to be neutral in a crisis situation; not reporting a crisis situation in such a manner that can rather deteriorate it. It is, on the basis of these that stations are expected to be guided by the NBC code in their operations in Nigeria. Unfortunately, however, NBS did not adopt the NBC code in the coverage of 2013-2015 herdsmen/ farmers crisis in Nasarawa State. It is on the basis of this kind of unethical coverage by the Nigeria electronic media that prone the NBS to sanction NTA, AIT, Channels, others to a total of 45 station to pay highest sum in the history of NBS penalty in Nigeria (www.odogwublog.com. Feb.10, 2019) 


\section{Recommendations}

Based on findings by this study, the following recommendations are hereby made:

- Supervision by NBC: The National Broadcasting Commission should be more proactive in checking the activities of broadcast organizations in Nigeria especially as Nigeria is currently bedeviled by insecurity owing to herdsmen, terrorists and bandit's activities.

- $\quad$ Sanction: Where it is discovered that a broadcast station, public or private is not operating according to the principles of NBC, such a station should be sanctioned by either withdrawal of its license, suspension for a particular period, or it should be heavily fined as seen during the electioneering campaigns in the 2019 general election in Nigeria where 45 station were fined for violating its provision.

- Workshop/ Conferences: Regular workshops or conferences should be organized for broadcasters and all stakeholders in the broadcast industry where they can be provided with information that can remind them of their responsibility to their society.

- $\quad$ Recruitment of Trained and Professional Personnel: It is disappointing that in Nigeria, despite the availability of many institutions offering mass communication and journalism courses, most of the people in the media industry are quacks. Broadcasting stations should send their untrained staff for training in the field or they should recruit only those that are trained.

- Holding firmly on the Social Responsibility Theory: Broadcasters, no matter the interest involved in a crisis situation, should always stick to the demands of the social responsibility theory on them. They should be selfdisciplined by being objective and fair to all parties in a news story.

\section{Acknowledgement}

The Authors would like to thank the management of Nasarawa State Polytechnic, Lafia, Nasarawa State, Nigeria for given them the opportunity to be shortlisted for sponsorship of this research base programme under the funding by Tertiary Education Trust Fund (TETFUND) 2017/ 2018 normal intervention programmes in Nigeria. We also thank the reviewers for their valuable input.

\section{References}

i. Ajala, V. (2011). Public relations in search of Professional Excellence. Ibadan: May Best Publications.

ii. Chaikaan, GJ. (2013). Broadcasting and the Broadcasting Media in Nigeria, 3rd edition. Makurdi: Azaben Publishers.

iii. Chaikaan, G.J. and Tsegyu, S. (2008). "Mass Media and Sustainable Development: Nigeria in focus” in International Journal of Development Studies, vol.3, No.I, pp.16-27

iv. Chiakaan, G.J. (2016). Application of PR in relationships management by tertiary institutions in Benue and Nasarawa States. An unpublished PhD thesis submitted to the postgraduate school, Benue State University, Nigeria.

v. Chiakaan, G.J. and Ahmad, J.I. (2014). Mass Communication for beginners. Makurdi: Azaben Publishers.

vi. Ciboh, R. (2007). Mass Media in Nigeria. Perspective on growth and Development. Makurdi: Aboki Publishers.

vii. Ciboh, R.S. and Iyorkyaa, T. (2004). News Writing. Makurdi: Aboki Publishers

viii. Conflicts in Nigeria (2010) www.ajol.infor.retrieved on 10th April, 2019

ix. Dominick, J. (1999). The Dynamics of Mass Communication. New York: McGraw Hill-Companies.

x. Folarin, B. (1998). Theories of Mass Communication: An Introductory Text. Ibadan: Stirling Holden Publishers.

xi. Madaki, W. M (2018). "Print Media Coverage of the 2011 Presidential Election Campaign in Nigeria; A study of Thisday and Leadership Newspaper in African General a management, Social Science and Humanities. Vol.7 N0.1/ 289-300.

xii. Madaki, W. M. (2019) comparative news framing of 2011 and 2015 presidential campaigns in Nigeria. An unpublished Ph.D. thesis submitted to the post graduate school, Benue state university, Nigeria.

xiii. Madaki, W. M; Kudu, B. (2014) Techniques of Reporting \& Newswriting: A Practical Approached, 2nd edition. Ibadan: Cobwels Book Publishers.

xiv. McQuail, D. (2005). Mass Communication Theories: An introduction. London: Sage Publications.

xv. National Broadcasting Commission (2012). The NBCCode $5^{\text {th }}$ edition. Abuja, Nigeria.

xvi. National Broadcasting Commission (2012). www.odogwublog.com. Feb. 10, 2019.

xvii. Ojebode, A. (2003). "Radio as a Development Communication Medium: Types, formats, roles and Limitations" in E. O. Soola (ed.), Communicating for Development Purposes. Ibadan; Kraft Books Ltd.

xviii. Okunna, C.A. (1999). Introduction to Mass Communication. Enugu: New Generation Books.

xix. Osuala, E. (2005). Introduction to research methodology. Lagos Africa-Frist Publishers.

xx. Sambe, J.A. (2005). Introduction to mass Communication Practice in Nigeria. Ibadan: Spectrum Books Ltd.

xxi. Talla, N.S., Apara, S.A., Aliyu, B.M. and Dawood, O.E. (2010). Peace studies and conflict resolution for Nigerian undergraduates. Jos: Star Links Communications.

xxii. ' Wright, C.R. (1975). Mass Communication: A sociological perspective, $2^{\text {nd }}$ edition. Canada: Random House, Inc.' 


\section{Appendix}

Data Collection Instrument

Department of Mass Communication

Nasarawa State Polytechnic,

Lafia,

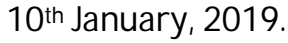

Request to Complete Questionnaire

We, (William M. Madaki, Anthony Orjiako and Gbaden J. Chiakaan, PhD.) of the above named Department and Taraba State University, Jalingo respectively currently undertaking a research on the Topic: An Appraisal of NBS Coverage a Communal Conflict in Nasarawa State, Nigeria: Focus on the 2013- 2015 Herdsmen/ Farmers Conflict. This is in fulfillment for the requirement of TERFUND Sponsorship for Academic Staff of Nasarawa State Polytechnic, Lafia, Nasarawa State, Nigeria.

I solicit your cooperation and request that you personally and honestly complete this questionnaire. The study is purely for academic purpose and the information provided by you will be treated in utmost confidence.

Your faithfully,

William M. madaki

Lead researcher

Chiakaan G.J. and

Anthony Orjiako. Co.

Researcher

Questionnaire

1. Do you have access to NBS programmes in your area?

Yes ( )

No ( )

2. How satisfied were you with the coverage of the 2013-2015 Fulani herdsmen and farmers crisis by NBS?

a. I was very satisfied

b. I was satisfied

c. I was not completely satisfied

d. I was not much satisfied

e. $\quad$ No comment

3. What can you say about the way and manner NBS covered the 2013-2015 herdsmen/ farmers crisis in Nasarawa

State

a. The station was fair and objective to the parties in the crisis

b. $\quad$ The station was biased in the coverage

c. The station was unethical and unprofessional in the coverage of the crisis

d. The language employed in the coverage of the crisis was offensive to one party

e. $\quad$ The station was not informing people accurately.

4. What do you think was the outcome of the way and manner NBS covered the 2013-2015 herdsmen/ farmers crisis in Nasarawa State?

a. It helped in managing the crisis to some extent

b. It contributed to management of the crisis to a large extent

c. It only succeeded in worsening the crisis situation

d. It succeeded in promoting more hatred and division among the elements in the State.

e. Many people did not have confidence in the station again.

Interview Guest Questions

1. Do you own radio set

2. Do you have access to NBS programmes in your area.

3. Were you satisfied by the way and manner NBS covered the 2013-2015 Fulani Herdsmen and Farmer crisis in Nasarawa state?

4. What can you say about the way and manner NBS covered the 2013-2015 Herdsmen/ Farmers crisis in Nasarawa State?

5. What do you suggest as solution to end these perennial conflicts between herdsmen/ farmers crisis in Nasarawa State. 